\title{
Risk scores and geriatric profile: can they really help us in anticoagulation decision making among older patients suffering from atrial fibrillation?
}

This article was published in the following Dove Press journal:

Clinical Interventions in Aging

I5 July 2014

Number of times this article has been viewed

\section{Frédéric Maes ${ }^{1, *}$ \\ Olivia Dalleur ${ }^{2,3, *}$ \\ Séverine Henrard ${ }^{4}$ \\ Dominique Wouters ${ }^{2}$ \\ Christophe Scavée ${ }^{1}$ \\ Anne Spinewine ${ }^{3,5}$ \\ Benoit Boland 4,6}

'Cardiology, Cliniques universitaires Saint-Luc, Université catholique de Louvain, Brussels, Belgium; ${ }^{2}$ Pharmacy Department, Cliniques universitaires Saint-Luc, Université catholique de Louvain, Brussels, Belgium; ${ }^{3}$ Louvain Drug Research Institute, Université catholique de Louvain, Brussels, Belgium; ${ }^{4}$ Institute of Health and Society (IRSS), Université catholique de Louvain, Brussels, Belgium; ${ }^{5}$ Pharmacy Department, CHU DinantGodinne, Université catholique de Louvain, Yvoir, Belgium; ${ }^{6}$ Geriatric Medicine, Cliniques universitaires Saint-Luc, Université catholique de Louvain, Brussels, Belgium

*The first two authors have contributed equally to the work

Correspondence: Olivia Dalleur Pharmacy Department, Cliniques universitaires Saint-Luc, Université catholique de Louvain, Av Hippocrate 10, 1200 Brussels, Belgium

Tel +32 27643681

Fax +32 27649129

Email olivia.dalleur@uclouvain.be
Objectives: Anticoagulation for the prevention of cardio-embolism is most frequently indicated but largely underused in frail older patients with atrial fibrillation (AF). This study aimed at identifying characteristics associated with anticoagulation underuse.

Methods: A cross-sectional study of consecutive geriatric patients aged $\geq 75$ years, with AF and clear anticoagulation indication $\left(\mathrm{CHADS}_{2}\right.$ [Congestive heart failure, Hypertension, Age $>75$, Diabetes mellitus, and prior Stroke or transient ischemic attack] $\geq 2$ ) upon hospital admission. All patients benefited from a comprehensive geriatric assessment. Their risks of stroke and bleeding were predicted using $\mathrm{CHADS}_{2}$ and HEMORR 2 HAGES (Hepatic or renal disease, Ethanol abuse, Malignancy, Older (age $>75$ years), Reduced platelet count or function, Rebleed risk, Hypertension (uncontrolled), Anemia, Genetic factors, Excessive fall risk, and Stroke) scores, respectively.

Results: Anticoagulation underuse was observed in 384 (50\%) of 773 geriatric patients with AF (median age 85 years; female 57\%, cognitive disorder 33\%, nursing home 20\%). No geriatric characteristic was found to be associated with anticoagulation underuse. Conversely, anticoagulation underuse was markedly increased in the patients treated with aspirin (odds ratio [OR] [95\% confidence interval]: $5.3[3.8 ; 7.5])$. Other independent predictors of anticoagulation underuse were ethanol abuse (OR: $4.0[1.4 ; 13.3]$ ) and age $\geq 90$ years (OR: 2.0 [1.2; 3.4]). Anticoagulation underuse was not inferior in patients with a lower bleeding risk and/or a higher stroke risk and underuse was surprisingly not inferior either in the AF patients who had previously had a stroke.

Conclusion: Half of this geriatric population did not receive any anticoagulation despite a clear indication, regardless of their individual bleeding or stroke risks. Aspirin use is the main characteristic associated with anticoagulation underuse.

Keywords: atrial fibrillation, anticoagulation, antiplatelet therapy, geriatric medicine, underprescribing

\section{Introduction}

The underuse of indicated medications in elderly patients is currently, and increasingly under scrutiny and known to cause adverse outcomes. ${ }^{1}$ The particular issue of anticoagulation underuse in patients with atrial fibrillation (AF) is well documented, including in elderly patients. $^{2-8}$

$\mathrm{AF}$ is the most frequent cardiac arrhythmia in the elderly and its prevalence increases with age. ${ }^{9}$ Moreover, two-thirds of AF cases concern patients aged $\geq 75$ years, ${ }^{10}$ in whom AF prevalence exceeds 10\%. Consequently, AF management is everyday practice for physicians in charge of elderly patients. Guidelines on pharmacological management of AF recommend the use of antithrombotic agents, ${ }^{11,12}$ as this arrhythmia largely increases the risk for cardio-embolism and specifically stroke. ${ }^{13}$ Oral anticoagulant therapy, such as vitamin K antagonists (VKAs), is recommended in patients at 
high risk of stroke ( $\geq 4 \%$ per year), while antiplatelet agents offer a possible alternative in patients at low risk of stroke, an infrequent situation in frail older patients. ${ }^{11}$

The translation of these guidelines into clinical practice remains a challenge. ${ }^{14,15}$ Even if there is strong evidence that antithrombotic treatment is beneficial in elderly patients and might effectively prevent numerous ischemic strokes, ${ }^{16-18}$ data show that approximately half of the older patients suffering from AF do not receive the recommended cardio-embolic prophylaxis. ${ }^{19,20}$ As the Western population gets incessantly older and AF is highly prevalent in elderly patients, it is worth getting a better understanding of older patients' characteristics associated with anticoagulation underuse. Frailty, which increases the risk of stroke but not of major hemorrhages, has been reported to be associated with lower VKA use in a few studies. ${ }^{21,22}$ Patient-related reasons cited to refrain from the prescription of anticoagulant therapy in the elderly include strong contraindications, advanced age, comorbidities, a history or increased risk of bleeding,

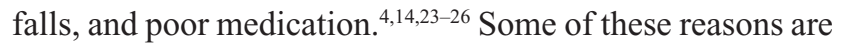
supported by evidence while others are not. Withholding anticoagulant therapy seems appropriate and legitimate in the presence of true contraindications (eg, previous major bleed, thrombopenia, poor compliance). In other cases (eg, risk of falls, advanced age), the risk-benefit ratio of anticoagulation is favorable. ${ }^{27}$ There is obviously a need for revisiting the prescription of anticoagulant therapy in the light of the individual assessment of the overall risks and benefits. The perception of the opposite risks of stroke and bleeding varies among physicians ${ }^{25,28}$ and remains highly challenging.

Tools are currently available to help physicians assess these two risks (clotting or bleeding) in older patients with AF, ie, the $\mathrm{CHADS}_{2}$ score (Congestive heart failure, Hypertension, Age $>75$, Diabetes mellitus, and prior Stroke or transient ischemic attack) to predict the annual stroke risk, ${ }^{29}$ and the HEMORR 2 HAGES score (Hepatic or renal disease, Ethanol abuse, Malignancy, Older [age $>75$ years], Reduced platelet count or function, Rebleed risk, Hypertension [uncontrolled], Anemia, Genetic factors, Excessive fall risk, and Stroke) ${ }^{30}$ to predict the risk of major bleeding. The aim of this study was to identify characteristics related to the underuse of anticoagulant therapy in geriatric patients in the light of their bleeding and cardio-embolism risk profile.

\section{Materials and methods}

\section{Study design and patient population}

We conducted a cross-sectional study including consecutive older patients with AF admitted between January 2008 and December 2010 in the Cliniques universitaires Saint-Luc,
Brussels, Belgium. Inclusion criteria were: 1) older age ( $\geq 75$ years); 2) evidence of current or recent AF; 3) indication for anticoagulation defined by a $\mathrm{CHADS}_{2}{ }^{29}$ score $\geq 2$; and 4) comprehensive geriatric assessment (multi-disciplinary assessment including medical aspects but also psycho-social and relational evaluation, nutritional assessment and physio/ ergotherapy testing) by the acute geriatric unit or the inpatient geriatric consultation team (providing geriatric counseling in non-geriatric wards for older patients with frailty defined by an Identification of Seniors at Risk [ISAR] score $\geq 2) .{ }^{31}$ We excluded the few patients with another indication for anticoagulants (eg, prosthetic valve, a history of deep venous thrombosis/pulmonary embolism in the last 6 months) or with anticoagulants contraindication (surgery in the last 3 weeks, peptic ulcer in the last 3 months).

\section{Data collection}

Socio-demographic data included age, sex, and residency (private home versus nursing home). Geriatric profile was assessed through functional dependency for basic activities of daily living using the Katz scale, ${ }^{32}$ frailty profile (ISAR) and the presence of cognitive disorders (clinical diagnosis or Mini Mental State Examination <24/30), ${ }^{33}$ malnutrition (assessed on the basis of a nutritionist evaluation and/or a body mass index of $<21 \mathrm{~kg} / \mathrm{m}^{2}$ and/or a mid-arm circumference $<23 \mathrm{~cm}$ and/or albumin $<3 \mathrm{~g} / \mathrm{dL}$ ), history of recent falls (within the previous 6 weeks), and elevated risk of falls (history of falls, dementia, Parkinson's disease, or evidence according to the team's physiotherapist). The use of antiplatelet therapy and/ or anticoagulation therapy (VKAs or low molecular weight heparin at a dosage offering effective anticoagulation) at home the day before admission was recorded. The new oral anticoagulants (NOACs, ie, apixaban, dabigatran, rivaroxaban) were not marketed in Belgium for cardio-embolic prevention in AF before the end of this study. Medical data specifically included the presence or absence of all the items of the $\mathrm{CHADS}_{2}$ and the HEMORR 2 HAGES scores.

\section{Scores of cardio-embolism and bleeding risks}

The AF-related risks of stroke and of bleeding were assessed using, respectively, the $\mathrm{CHADS}_{2}$ score $^{29}$ and the HEMOR$\mathrm{R}_{2}$ HAGES score. ${ }^{30}$ We chose to use the $\mathrm{CHADS}_{2}$ score for several reasons. In contrast to the $\mathrm{CHA}_{2} \mathrm{DS}_{2}-\mathrm{VASc}$ score (Congestive heart failure, Hypertension, Age $<75$ years, Diabetes mellitus, Stroke, Vascular disease, Age 65-74 years, Sex category) ${ }^{34}$ (recently developed to identify AF patients at very low risk of cardio-embolism who do not require anticoagulation, ie, a very infrequent situation in frail older 
patients), the $\mathrm{CHADS}_{2}$ score: 1) was developed in a population of older patients; 2) correlates with the stroke risk in a linear, precise (narrow confidence intervals), and valid (C statistics) manner; 3) correlates with the prescription habits in geriatric patients; ${ }^{35} 4$ ) is easy to remember and to use in the daily practice; and 5) was available at the time of anticoagulation decision in this study. Moreover, according to the $\mathrm{CHA}_{2} \mathrm{DS}_{2}$-VASc score, all the patients aged $>75$ years should be on anticoagulation, which is controversial in older patients with lower annual stroke risk $(<4 \%)$ and significant bleeding risk. The $\mathrm{CHADS}_{2}$ score (range 2-6/6 in this study) gives one point for the presence of each cardio-embolism risk factor, namely congestive heart failure (within the previous year), hypertension (antihypertensive regimen or $\geq 160 / 90 \mathrm{mmHg}$ on several occasions), age $\geq 75$ years, diabetes mellitus or anti-diabetic drugs or fasting blood glucose $\geq 126 \mathrm{mg} / \mathrm{dL}$ on several occasions, and two points for stroke or transient ischemic attack (TIA) history.

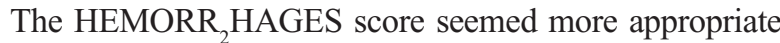
to us than the more recent HAS-BLED score (Hypertension, Abnormal renal/liver function, Stroke, Bleeding history or predisposition, Labile international normalized ratio, Elderly [ $>65$ years], Drugs/alcohol concomitantly ${ }^{36}$ for the following reasons: 1) it was developed in a population of older patients; 2 ) it includes items relevant to a geriatric population (eg, age $>75$ years, malignancy, anemia, reduced platelet function due to antiplatelet therapy, and elevated falls risk); 3 ) it precisely predicts (narrow confidence intervals) the risk of major bleeding events when treated by anticoagulation; 4) it correlates with the actual prescription of anticoagulants in geriatric patients. ${ }^{35}$ These features are not present in the HASBLED score. Furthermore, the HAS-BLED item "labile international normalized ratios (INRs)" item was not available at the time of decision-making on starting anticoagulation. ${ }^{36} \mathrm{HEM}-$ ORR $R_{2}$ AGES is the most suitable score to assess bleeding risk in older patients according to a recent French expert consensus on the management of AF in older people. ${ }^{10}$

The HEMORR ${ }_{2}$ HAGES score (range 1-12/12 in this study) is computed by adding one point for each of the following bleeding risk factors: hepatic (cirrhosis with Child-Pugh score $\geq 3$ ) or renal failure (estimated glomerular filtration rate $^{37}<30 \mathrm{~mL} / \mathrm{min}$ ), ethanol abuse, malignancy, older age, reduced platelet count $(<150,000 / \mu \mathrm{L}$ ) or function (use of platelet aggregation inhibitors), uncontrolled hypertension, anemia (hemoglobin $<10 \mathrm{~g} / \mathrm{dL}$ ), genetic factors, elevated falls risk, stroke, and by adding two points for rebleed risk, ie, history of a major bleeding event (hemoglobin decline of $\geq 2 \mathrm{~g} / \mathrm{dL}$, blood transfusion of $\geq 2$ units, or bleeding in a major organ) and recent bleeding (last 3 years). ${ }^{38}$

\section{Objectives}

The aim of our study was to first assess the underuse of anticoagulation (VKA or low molecular weight heparin at full therapeutic dosage) before hospital admission in older patients with clear clinical indication of anticoagulation according to the CHADS 2 score. Secondly, we wanted to better characterize these non-anticoagulated patients regarding their cardiovascular and geriatric profile and their $\mathrm{CHADS}_{2}$ and HEMORR 2 HAGES scores in order to search for modifiable characteristics associated with anticoagulation underuse.

\section{Statistical analysis}

All continuous variables not normally distributed were summarized using the median and the inter-quartile range $\left[\mathrm{P}_{25}-\mathrm{P}_{75}\right]$ and were compared between groups using Wilcoxon rank sum test or Kruskal-Wallis test, depending on the number of groups in the comparison. Categorical variables were expressed using percentages and were compared using chi-squared test or the Fisher's exact test, as appropriate. Multivariate logistic regression was used to assess the independent predictors of anticoagulation underuse among the total cohort as well as in this subgroup of patients with a history of stroke. In order to avoid co-linearity, the correlation coefficients between covariates were calculated. In case of co-linearity ( $r$-value $>0.90$ ), only one of the two covariates was considered in the multivariate model. Variables with a $P$-value $\leq 0.20$ in univariate analysis were submitted to the multivariate model. A stepwise procedure using Akaike's information criterion was used to select independent multivariate predictors of anticoagulation underuse. Model goodness of fit was examined using Hosmer-Lemeshow test (null hypothesis: the model is a good fit for the data). All statistical analyses were performed using $\mathrm{R}$ version 2.15.1 (R Foundation for Statistical Computing) and a $P$-value $<0.05$ was considered as statistically significant.

\section{Results \\ Patient characteristics}

Seven hundred and seventy-three older patients (median age 85.0 years, female sex $57 \%$ ) met the inclusion criteria. Geriatric syndromes were frequent (eg, malnutrition $47 \%$, recent falls $42 \%$, cognitive disorders $33 \%$ ). Half of the patients were dependent (median Katz score: 9) and one fifth were nursing home residents.

The annual risk of stroke was high (mean \pm standard deviation $[\mathrm{SD}]: 6.9 \% \pm 3.3 \%$, median $5.9 \%$ ) as predicted by the $\mathrm{CHADS}_{2}$ score and its items (congestive heart failure $49 \%$, hypertension $83 \%$, age $\geq 75$ years $100 \%$, diabetes $21 \%$, 
and stroke/TIA $32 \%$ ). The annual risk of bleeding was also high (mean \pm SD: $9.7 \% \pm 2.2 \%$, median $10.4 \%$ ), based on the HEMORR ${ }_{2}$ HAGES score and its prevalent items (eg, risk of falls $63 \%$, reduced platelet function/count $56 \%$, in addition to older age, hypertension and stroke history).

\section{Underuse of anticoagulation}

Of these 733 patients with indication for anticoagulant therapy, half $(50.3 \%, n=389)$ were on VKA $(n=330)$ or low molecular weight heparin $(n=59)$, while the other half was not anticoagulated $(49.7 \%, \mathrm{n}=384)$ at home before hospital admission. Among the 330 patients on VKA treatment, the admission INR was infra-therapeutic (INR $<2$ ) in $56 \%$, on target $(2<$ INR $<3)$ in $21 \%$ and supra-therapeutic (INR $>3$ ) in $22 \%$ (admission INR unknown in 4 patients $=1 \%$ ). Table 1 compares patients on anticoagulation to those with no anticoagulation in terms of socio-demographic data, geriatric syndromes as well as risk factors and predicted annual rates of stroke and bleeding.

Patients with no anticoagulation had significantly higher use of antiplatelet therapy (61\% versus $27 \%, P<0.001)$, less thrombopenia $(7.0 \%$ versus $18.3 \%, P<0.001)$, older age ( 86 versus 85 years, $P=0.004$ ), and higher annual bleeding risk according to HEMORR ${ }_{2}$ HAGES $(P<0.001)$. However, the latter was not different when corrected for use of antiplatelet agents (ie, withdrawing one point to all the patients on antiplatelet therapy, 8.4 [8.4; $10.4]$ versus 8.4 [8.4; 10.4], $P=0.41$ ).

Univariate analysis confirmed that anticoagulation underuse was neither associated with geriatric syndromes

Table I Characteristics of older patients with atrial fibrillation regarding their anticoagulation status

\begin{tabular}{|c|c|c|c|}
\hline & $\begin{array}{l}\text { On anticoagulation } \\
\mathrm{n}=389\end{array}$ & $\begin{array}{l}\text { No anticoagulation } \\
n=384\end{array}$ & $P$-value \\
\hline \multicolumn{4}{|l|}{ Socio-demographic } \\
\hline Age, median $\left[\mathrm{P}_{25}-\mathrm{P}_{75}\right]$ & $85[8 \mid-88]$ & 86 [82-89] & 0.004 \\
\hline Female sex, \% & 54.8 & 58.6 & 0.28 \\
\hline Living in nursing home, \% & 17.2 & 23.2 & 0.04 \\
\hline \multicolumn{4}{|l|}{ Geriatric features, $\%$} \\
\hline Malnutrition & 45.0 & 48.6 & 0.32 \\
\hline Recent falls & 42.7 & 42.2 & 0.89 \\
\hline Cognitive disorders & 31.9 & 34.6 & 0.42 \\
\hline Dependency in ADL (Katz $\geq 10 / 24)$ & 45.9 & 49.3 & 0.33 \\
\hline \multicolumn{4}{|l|}{$\mathrm{CHADS}_{2}$, stroke risk } \\
\hline Score, median $\left[\mathrm{P}_{25}-\mathrm{P}_{75}\right]$ & $3[2-4]$ & $3[2-4]$ & 0.17 \\
\hline $\begin{array}{l}\text { Risk, \%/year, median }\left[\mathrm{P}_{25}-\mathrm{P}_{75}\right] \\
\text { Items, \% }\end{array}$ & $5.9[4.0-8.5]$ & $5.9[4.0-8.5]$ & \\
\hline Congestive heart failure & 50.4 & 47.1 & 0.37 \\
\hline Hypertension & 82.2 & 83.1 & 0.77 \\
\hline Age $\geq 75$ years & 100 & 100 & \\
\hline Diabetes mellitus & 21.6 & 21.0 & 0.80 \\
\hline Stroke or TIA & 34.0 & 30.7 & 0.34 \\
\hline \multicolumn{4}{|l|}{ HEMORR ${ }_{2}$ HAGES, bleeding risk } \\
\hline Score, $\%$ median $\left[\mathrm{P}_{25}-\mathrm{P}_{75}\right]$ & $4[3-4]$ & $4[3-5]$ & $<0.001$ \\
\hline $\begin{array}{l}\text { Risk, \%/year, median }\left[\mathrm{P}_{25}-\mathrm{P}_{75}\right] \\
\text { Items, \% }\end{array}$ & $10.4[8.4-10.4]$ & $10.4[8.4-12.3]$ & \\
\hline Hepatic/renal failure & 14.6 & 13.8 & 0.74 \\
\hline $\mathrm{eGFR}<30 \mathrm{~mL} / \mathrm{min}$ & 13.4 & 11.5 & 0.42 \\
\hline Ethanol abuse & 1.3 & 3.6 & 0.03 \\
\hline Malignancy & 9.0 & 10.7 & 0.43 \\
\hline Reduced platelets & 45.0 & 68.0 & $<0.001$ \\
\hline Antiplatelet therapy & 26.5 & 60.7 & $<0.001$ \\
\hline Thrombocytopenia & 18.3 & 7.0 & $<0.001$ \\
\hline Rebleed risk & 6.9 & 4.9 & 0.24 \\
\hline Anemia $(\mathrm{Hb}<10 \mathrm{~g} / \mathrm{dL})$ & 16.5 & 16.9 & 0.86 \\
\hline Elevated falls risk & 60.4 & 65.4 & 0.15 \\
\hline Stroke & 30.8 & 28.4 & 0.45 \\
\hline
\end{tabular}

Abbreviations: ADL, activities in daily living; eGFR, estimated glomerular filtration rate (using the Modification of Diet in Renal Disease Study-4 formula); Hb, hemoglobin; TIA, transient ischemic attack; CHADS 2 , Congestive heart failure, Hypertension, Age $>75$, Diabetes mellitus, and prior Stroke or transient ischemic attack; HEMORR ${ }_{2}$ HAGES, Hepatic or renal disease, Ethanol abuse, Malignancy, Older (age $>75$ years), Reduced platelet count or function, Rebleed risk, Hypertension (uncontrolled), Anemia, Genetic factors, Excessive fall risk, and Stroke. 
Table 2 Determinants of anticoagulation underuse in the study population $(n=773)$

\begin{tabular}{|c|c|c|c|c|c|c|}
\hline & \multicolumn{3}{|c|}{ Univariate analysis } & \multicolumn{3}{|c|}{ Multivariate analysis } \\
\hline & OR & {$[95 \% \mathrm{CI}]$} & $P$-value & OR & {$[95 \% \mathrm{CI}]$} & $P$-value \\
\hline Antiplatelet use & 4.28 & [3.17-5.83] & $<0.00 \mathrm{I}$ & 5.27 & {$[3.75-7.48]$} & $<0.001$ \\
\hline Ethanol abuse & 2.91 & [1.10-9.07] & 0.043 & 4.00 & {$[1.39-|3.3|]$} & 0.014 \\
\hline \multicolumn{7}{|l|}{ Age } \\
\hline$\geq 90$ years & 1.67 & [I.03-2.7I] & 0.039 & 2.00 & {$[1.18-3.43]$} & 0.011 \\
\hline$\geq 85$ and $<90$ years & 1.07 & {$[0.70-4.66]$} & 0.745 & 1.11 & [0.69-1.79] & 0.673 \\
\hline$\geq 80$ and $<85$ years & 0.99 & [0.64-I.54] & 0.976 & 0.86 & {$[0.53-1.40]$} & 0.549 \\
\hline$\geq 75$ and $<80$ years & 1.00 & & & 1.00 & & \\
\hline Elevated falls risk & 1.24 & [0.92-1.66] & 0.154 & 1.36 & {$[0.95-1.93]$} & 0.090 \\
\hline Living in nursing home & 1.45 & {$[1.02-2.08]$} & 0.038 & 1.37 & {$[0.93-2.03]$} & 0.115 \\
\hline
\end{tabular}

Note: Hosmer-Lemeshow goodness-of-fit $P$-value $=0.76$, indicating that the model is a good fit for the data.

Abbreviations: $\mathrm{OR}$, odds ratio; $\mathrm{Cl}$, confidence interval.

(malnutrition, falls, cognitive disorders, functional dependency) nor with the $\mathrm{CHADS}_{2}$ score. Potential risk factors ( $P$-value $\leq 0.2)$ of anticoagulation underuse were antiplatelet therapy, ethanol abuse, age $>90$ years, falls risk, and nursing home residency (Table 2, left column). The HEMORR 2 HAGES score, which includes three of the abovementioned risk factors (ethanol abuse, antiplatelet therapy and falls risk), was associated with anticoagulation underuse in the univariate analysis. However, the multivariate analysis (Table 2, right column) identified three variables as independent predictors of anticoagulation underuse, namely antiplatelet therapy (OR 5.3), ethanol abuse (OR 4.0) - a feature present in only $2.5 \%$ of the patients - and age $>90$ years (OR 2.0).

\section{Anticoagulation underuse and antiplatelet therapy}

As antiplatelet therapy was the strongest determinant of anticoagulation underuse, we raised the hypothesis that patients on antiplatelet agents but no anticoagulation $(\mathrm{n}=233)$ had been at higher bleeding risk (HEMORR ${ }_{2}$ HAGES score) and/or lower stroke risk (CHADS ${ }_{2}$ score) than those on anticoagulation $(n=389)$. Table 3 shows that this was not the case. These two groups did not show a difference in the $\mathrm{CHADS}_{2}$ score nor in the HEMORR ${ }_{2}$ HAGES score corrected for use of antiplatelet agents (ie, withdrawing one point to all the patients on antiplatelet therapy). In stable vascular disease, antiplatelets can indeed be stopped in patients under anticoagulant treatment. ${ }^{10,11,39,40}$

\section{Anticoagulation underuse after stroke}

We further studied the 229 patients with AF and a history of stroke, in whom anticoagulation underuse was expected to be lower. Surprisingly, anticoagulation underuse was present in 109 (48\%) of these patients with a previous stroke, and not lower than in those free of stroke (51\%) $(P=0.45)$. The geriatric profile of these 229 frail older stroke patients

Table 3 Comparison between patients on anticoagulant and patients on antiplatelet agents

\begin{tabular}{|c|c|c|c|}
\hline & $\begin{array}{l}\text { Anticoagulant }^{a} \\
(n=389)\end{array}$ & $\begin{array}{l}\text { Antiplatelet } \\
(n=233)\end{array}$ & P-value \\
\hline \multicolumn{4}{|l|}{ Significant variables, $\%$} \\
\hline Antiplatelet therapy & 26.5 & 100 & $<0.001$ \\
\hline Vascular disease & 48.9 & 62.2 & 0.003 \\
\hline Ethanol abuse & 1.3 & 3.9 & 0.036 \\
\hline \multicolumn{4}{|l|}{ Risk prediction } \\
\hline \multicolumn{4}{|l|}{$\mathrm{CHADS}_{2}$ score } \\
\hline Median score $\left[\mathrm{P}_{25}-\mathrm{P}_{75}\right]$ & $3[2-4]$ & $3[2-4]$ & NS \\
\hline Risk, \%/year, median $\left[\mathrm{P}_{25}-\mathrm{P}_{75}\right]$ & $5.9[4.0-8.5]$ & $5.9[4.0-8.5]$ & \\
\hline \multicolumn{4}{|l|}{$\mathrm{HEMORR}_{2}$ HAGES score } \\
\hline Median score $\left[\mathrm{P}_{25}-\mathrm{P}_{75}\right]$ & $4[3-4]$ & $4[4-5]$ & $<0.001$ \\
\hline Risk, \%/year, median $\left[\mathrm{P}_{25}-\mathrm{P}_{75}\right]$ & $10.4[8.4-10.4]$ & $10.4[10.4-12.3]$ & \\
\hline \multicolumn{4}{|l|}{ Corrected HEMORR ${ }_{2}$ HAGES score ${ }^{c}$} \\
\hline Median score $\left[\mathrm{P}_{25}-\mathrm{P}_{75}\right]$ & $3[3-4]$ & $3[3-4]$ & NS \\
\hline Risk, \%/year, median $\left[\mathrm{P}_{25}-\mathrm{P}_{75}\right]$ & $8.4[8.4-10.4]$ & $8.4[8.4-10.4]$ & \\
\hline
\end{tabular}

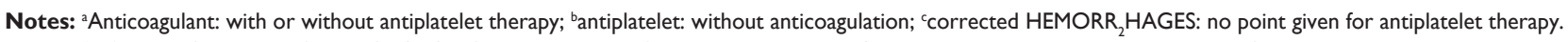
Abbreviations: NS, non-significant; $\mathrm{CHADS}_{2}$, Congestive heart failure, Hypertension, Age $>75$, Diabetes mellitus, and prior Stroke or transient ischemic attack; HEMORR ${ }_{2}$ HAGES, Hepatic or renal disease, Ethanol abuse, Malignancy, Older (age $>75$ years), Reduced platelet count or function, Rebleed risk, Hypertension (uncontrolled), Anemia, Genetic factors, Excessive fall risk, and Stroke. 
(median age 85 years, female 52\%, nursing home 27\%) was similar to that of the overall study group. In multivariate analysis, the single independent factor associated with anticoagulation underuse in these stroke patients was antiplatelet agent use (OR [95\% CI]: 5.0 [2.9; 8.8]) $(P<0.001)$. Neither

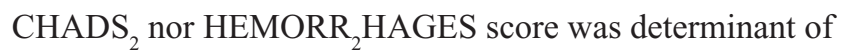
anticoagulation underuse in patients with AF and stroke.

\section{Discussion}

The main finding of this study in frail older patients with AF was that the strongest predictor of anticoagulation underuse was the use of antiplatelet therapy, a reversible characteristic allowing improvement in prescribing and stroke prevention. Aspirin (acetylsalicylic acid) is known to be of limited efficacy in stroke prevention, ${ }^{41}$ especially as age increases. ${ }^{42}$ Warfarin is more effective than aspirin, also in older patients. ${ }^{43}$ Moreover, warfarin is safer than aspirin in octogenarians, as shown in the WASPO trial (warfarin versus aspirin for stroke prevention in octogenarians with atrial fibrillation), which found significantly more adverse events with aspirin (33\%) than with warfarin (6\%), including serious bleeding. ${ }^{44}$ Surprisingly, the large anticoagulation underuse $(69 \%)$ in our patients on antiplatelet therapy was not explained by a lower risk of cardio-embolism or a higher risk of bleeding. Thus, we found no clinical rationale underlying the withholding of anticoagulation. We suspect that aspirin was prescribed in some patients for AF-related stroke prevention, while in the others - the majority probably - for underlying cardiovascular ischemic disease. It has been proposed not to add aspirin for associated stable vascular disease $\mathrm{e}^{45}$ in patients with AF receiving anticoagulation, as there is no evidence that adding aspirin to warfarin reduces stroke or other vascular events in these patients. ${ }^{39,46}$ In such patients, in line with recent guidelines, we suggest that aspirin be withdrawn and anticoagulation prescribed in monotherapy if the coronary ischemic event occurred more than 1 year ago. ${ }^{18,47}$

The observation that history of stroke was not related to higher use of anticoagulation is another important finding of our study. Nearly half (48\%) of these high risk patients in secondary stroke prevention presented with anticoagulation underuse, despite no significant difference in their geriatric profile, stroke risk or bleeding risk. A similar observation was reported in elderly patients with AF and recent ischemic stroke, in whom warfarin use decreased with age, ${ }^{6}$ a finding not observed in our study. However, we have not considered possible hemorrhagic conversion of stroke as potential cause of not prescribing anticoagulant therapy.
Medical decision making in terms of anticoagulation in older patients is complex. The more advanced the age, the higher the risks of both clotting and bleeding. Warfarin and other VKAs are feared by clinicians in the elderly because of complex kinetics, multiple interactions, and narrow therapeutic index. We used the $\mathrm{CHADS}_{2}$ and the HEMORR 2 HAGES scores, which offer several advantages in the elderly population. However, these tools also present limitations, including the inclusion of similar items. Neither the $\mathrm{CHADS}_{2}$ score nor the corrected HEMORR ${ }_{2}$ HAGES score was found to be an independent determinant of VKA underuse in our hospital admitted patients. Our observations differ from those reported in long-term care residents where warfarin use increased with higher stroke risk and with lower bleeding risk. ${ }^{48}$ Our results confirm the observation of Marcucci et al that cardio-embolic and bleeding risks are not the main determinants of the therapeutic choice in elderly patients with AF. ${ }^{19}$

We believe that risk prediction tools, eg, the $\mathrm{CHADS}_{2}$ and the HEMORR ${ }_{2}$ HAGES scores, should be used more generally in primary care practice to help physicians balance the risk-benefit ratio for anticoagulation in individual frail older patients, who are often at high risk of thromboembolism and bleeding. On one hand the $\mathrm{CHADS}_{2}$ score predicts cardioembolism events, which imply significant morbi-mortality, and on the other hand the HEMORR 2 HAGES score predicts "major bleedings" without any distinction between muscular or digestive bleedings, which are manageable, and intracranial or life-threatening bleedings. Maybe we should consider weighting this "global bleeding" risk score in order to allow a reasonable comparison between both risk scores and so determine the net clinical benefit for the patient more accurately, especially at the cerebral level. This is a crucial point knowing that Friberg et $\mathrm{al}^{49}$ already demonstrated that the cerebral risk of ischemic stroke without anticoagulant treatment exceeds the cerebral risk of intracranial bleeding with anticoagulant treatment at almost every combination of stroke and bleeding risks.

Our study confirms the general tendency among physicians to underuse anticoagulants in the elderly with AF. This large underuse rate $(\sim 50 \%)$ is concordant with previous literature data. ${ }^{19,20,25,50-54}$ Besides antiplatelet therapy, discussed above, two other characteristics were found to be independent predictors of anticoagulation underuse in our multivariate analysis: ethanol abuse and patient's very old age ( $\geq 90$ years). The former was infrequent and strong, while the latter was frequent and weak. Although age is an independent risk factor for bleeding with all anticoagulation 
modalities, ${ }^{42,55}$ age should not be regarded as a contraindication to anticoagulation treatment. In a large study on very old patients (median age 84 years) on VKA carefully monitored by anticoagulation clinics, the rate of major bleeding was low (1.9\%/year). ${ }^{56}$ Moreover, the risk for stroke increases with older age in patients with AF.9,57 Therefore, the withholding of anticoagulation for the sole reason of older age can be considered as ageism. ${ }^{1}$ We did not find any association between anticoagulation underuse and geriatric syndromes, as reported by De Breucker et al (dementia, malnutrition, functional dependency, risk of falls), ${ }^{20}$ or Sanchez-Barba et al (depression, cognitive disorders), ${ }^{22}$ neither with sex, hemorrhage history or malignancy. ${ }^{19,58}$

Our study presents several strengths. Firstly, it focuses on a highly relevant and complex topic in the daily medical practice, as the elderly population constantly grows and anticoagulation drugs are frequent long-term medications in elderly patients. Secondly, it is quite original, as few previous studies analyzed both medical and geriatric characteristics as potential predictors of anticoagulation underuse in a large and representative frail older population with AF. Thirdly, there is currently little data in literature comparing both risk scores in a face-to-face way, especially among geriatric patients. ${ }^{59}$

The study shows some limitations. It was cross-sectional and based on assessments conducted during a hospital stay and from patients recruited from our single center. Nevertheless, we had access to a large population, the pharmacological treatment used at home, and a valuable amount of information from the comprehensive geriatric assessment. We could not explore all the potential factors affecting the anticoagulation decision, particularly the general practitioner-related reasons or the patient's preferences. It has already been demonstrated that anticoagulation under-prescribing is partially explained by the fact that general practitioners would feel personally responsible for an iatrogenic hemorrhagic complication, as opposed to a cardio-embolic complication in the absence of treatment. ${ }^{60}$ In the same way, it was not possible to evaluate patients' compliance and psychosocial factors that could significantly influence the bleeding risk. ${ }^{61} \mathrm{We}$ think qualitative and prospective work would help to understand reasons underlying anticoagulant underuse.

This study was conducted before the marketing of NOACs in our country (2012), nowadays used in AF. We believe that these NOACs will be of little help in decreasing the anticoagulation underuse during the coming years in the frail older population. Due to a short half-life, treatment adherence remains a challenge with these drugs. The lack of reliable monitoring tests and of reversal agents, and cost are other barriers to the prescribing of NOACs, which were not encountered with VKAs. ${ }^{62}$ Three characteristics associated with anticoagulation underuse in our study, namely renal impairment, antiplatelet use, and ethanol abuse, will not disappear with the use of NOACs. We believe that the decision to prescribe anticoagulation is a global concept and that the type of molecule (VKA versus NOAC) is not significantly influencing the decision-making in this specific population. Future studies should compare the prevalence of underuse after the marketing of NOACs with the present results in order to test this hypothesis.

In summary, our study showed that underuse of anticoagulation concerns half of the frail older patients with AF and anticoagulation indication. Underuse of anticoagulation could not be clinically explained in this population, and was mainly related to the use of aspirin. In this context, risk scores may be useful to help the clinician in the decision making process. Nevertheless, the net clinical benefit remains difficult to assess knowing that these scores predict events of varying severity and therefore remain difficult to compare for each individual case.

\section{Acknowledgment}

O Dalleur received funding from the Federal Public Service Health of the Belgian government as part of a national project on implementation of clinical pharmacy in hospitals.

\section{Disclosure}

The authors declare that they have no financial or personal relationships with the manufacturers or with other people or organizations that could inappropriately influence this work.

\section{References}

1. Cherubini A, Corsonello A, Lattanzio F. Underprescription of beneficial medicines in older people: causes, consequences and prevention. Drugs Aging. 2012;29(6):463-475.

2. Monte S, Macchia A, Pellegrini F, et al. Antithrombotic treatment is strongly underused despite reducing overall mortality among high-risk elderly patients hospitalized with atrial fibrillation. Eur Heart J. 2006; 27(18):2217-2223.

3. Frewen J, Finucane C, Cronin H, et al. Atrial fibrillation is under recognised and inappropriately treated in older adults: cross-sectional findings from the Irish Longitudinal study on Ageing (TILDA). Age Ageing. 2013;42(suppl 2):ii4.

4. Pugh D, Pugh J, Mead GE. Attitudes of physicians regarding anticoagulation for atrial fibrillation: a systematic review. Age Ageing. 2011; 40(6):675-683.

5. Ogilvie IM, Newton N, Welner SA, Cowell W, Lip GY. Underuse of oral anticoagulants in atrial fibrillation: a systematic review. Am J Med. 2010;123(7):638-645.e4.

6. Brass LM, Krumholz HM, Scinto JD, Mathur D, Radford M. Warfarin use following ischemic stroke among Medicare patients with atrial fibrillation. Arch Intern Med. 1998;158(19):2093-2100. 
7. Flaker GC, McGowan DJ, Boechler M, Fortune G, Gage B. Underutilization of antithrombotic therapy in elderly rural patients with atrial fibrillation. Am Heart J. 1999;137(2):307-312.

8. Lau E, Bungard TJ, Tsuyuki RT. Stroke prophylaxis in institutionalized elderly patients with atrial fibrillation. J Am Geriatr Soc. 2004;52(3): 428-433.

9. Rich MW. Epidemiology of atrial fibrillation. $J$ Interv Card Electrophysiol. 2009;25(1):3-8.

10. Hanon O, Assayag P, Belmin J, et al. Expert consensus of the French Society of Geriatrics and Gerontology and the French Society of Cardiology on the management of atrial fibrillation in elderly people. Arch Cardiovasc Dis. 2013;106(5):303-323.

11. Anderson JL, Halperin JL, Albert NM, et al. Management of Patients With Atrial Fibrillation (Compilation of 2006 ACCF/AHA/ESC and 2011 ACCF/AHA/HRS Recommendations): A Report of the American College of Cardiology/American Heart Association Task Force on Practice Guidelines. J Am Coll Cardiol. 2013;61(18):1935-1944.

12. European Heart Rhythm Association, European Association for CardioThoracic Surgery, Camm AJ, et al. Guidelines for the management of atrial fibrillation: the Task Force for the Management of Atrial Fibrillation of the European Society of Cardiology (ESC). Eur Heart J. 2010; 31(19):2369-2429.

13. Wolf PA, Abbott RD, Kannel WB. Atrial fibrillation: a major contributor to stroke in the elderly. The Framingham Study. Arch Intern Med. 1987;147(9):1561-1564.

14. Hylek EM, D'Antonio J, Evans-Molina C, Shea C, Henault LE, Regan S. Translating the results of randomized trials into clinical practice: the challenge of warfarin candidacy among hospitalized elderly patients with atrial fibrillation. Stroke. 2006;37(4):1075-1080.

15. Wittkowsky AK. Effective anticoagulation therapy: defining the gap between clinical studies and clinical practice. Am J Manag Care. 2004;10(10 Suppl):S297-S306; discussion S312-S317.

16. Gladstone DJ, Bui E, Fang J, et al. Potentially preventable strokes in high-risk patients with atrial fibrillation who are not adequately anticoagulated. Stroke. 2009;40(1):235-240.

17. Pisters R, van Oostenbrugge RJ, Knottnerus IL, et al. The likelihood of decreasing strokes in atrial fibrillation patients by strict application of guidelines. Europace. 2010;12(6):779-784.

18. Aguilar MI, Hart R. Oral anticoagulants for preventing stroke in patients with non-valvular atrial fibrillation and no previous history of stroke or transient ischemic attacks. Cochrane Database Syst Rev. 2005;(3):CD001927.

19. Marcucci M, Iorio A, Nobili A, et al. Factors affecting adherence to guidelines for antithrombotic therapy in elderly patients with atrial fibrillation admitted to internal medicine wards. Eur J Intern Med. 2010;21(6):516-523.

20. De Breucker S, Herzog G, Pepersack T. Could geriatric characteristics explain the under-prescription of anticoagulation therapy for older patients admitted with atrial fibrillation? A retrospective observational study. Drugs Aging. 2010;27(10):807-813.

21. Perera V, Bajorek BV, Matthews S, Hilmer SN. The impact of frailty on the utilisation of antithrombotic therapy in older patients with atrial fibrillation. Age Ageing. 2009;38(2):156-162.

22. Sanchez-Barba B, Navarrete-Reyes AP, Avila-Funes JA. Are geriatric syndromes associated with reluctance to initiate oral anticoagulation therapy in elderly adults with nonvalvular atrial fibrillation? $J \mathrm{Am}$ Geriatr Soc. 2013;61(12):2236-2237.

23. Zarraga IG, Kron J. Oral anticoagulation in elderly adults with atrial fibrillation: integrating new options with old concepts. J Am Geriatr Soc. 2013;61(1):143-150.

24. Beyth RJ, Antani MR, Covinsky KE, et al. Why isn't warfarin prescribed to patients with nonrheumatic atrial fibrillation? J Gen Intern Med. 1996;11(12):721-728.

25. Monette J, Gurwitz JH, Rochon PA, Avorn J. Physician attitudes concerning warfarin for stroke prevention in atrial fibrillation: results of a survey of long-term care practitioners. J Am Geriatr Soc. 1997;45(9): 1060-1065.
26. Deplanque D, Leys D, Parnetti L, et al. Stroke prevention and atrial fibrillation: reasons leading to an inappropriate management. Main results of the SAFE II study. Br J Clin Pharmacol. 2004;57(6):798-806.

27. Man-Son-Hing M, Nichol G, Lau A, Laupacis A. Choosing antithrombotic therapy for elderly patients with atrial fibrillation who are at risk for falls. Arch Intern Med. 1999;159(7):677-685.

28. Anderson N, Fuller R, Dudley N. 'Rules of thumb' or reflective practice? Understanding senior physicians' decision-making about antithrombotic usage in atrial fibrillation. QJM. 2007;100(5):263-269.

29. Gage BF, Waterman AD, Shannon W, Boechler M, Rich MW, Radford MJ. Validation of clinical classification schemes for predicting stroke: results from the National Registry of Atrial Fibrillation. JAMA. 2001;285(22):2864-2870.

30. Gage BF, Yan Y, Milligan PE, et al. Clinical classification schemes for predicting hemorrhage: results from the National Registry of Atrial Fibrillation (NRAF). Am Heart J. 2006;151(3):713-719.

31. McCusker J, Bellavance F, Cardin S, Trepanier S, Verdon J, Ardman O. Detection of older people at increased risk of adverse health outcomes after an emergency visit: the ISAR screening tool. J Am Geriatr Soc. 1999; 47(10):1229-12237.

32. Katz S, Ford AB, Moskowitz RW, Jackson BA, Jaffe MW. Studies of Illness in the Aged. The Index of Adl: A Standardized Measure of Biological and Psychosocial Function. JAMA. 1963;185:914-919.

33. Folstein MF, Folstein SE, McHugh PR. "Mini-mental state". A practical method for grading the cognitive state of patients for the clinician. J Psychiatr Res. 1975;12(3):189-198.

34. Lip GY, Nieuwlaat R, Pisters R, Lane DA, Crijns HJ. Refining clinical risk stratification for predicting stroke and thromboembolism in atrial fibrillation using a novel risk factor-based approach: the euro heart survey on atrial fibrillation. Chest. 2010;137(2):263-272.

35. Somme D, Corvol A, Lazarovici C, Lahjibi-Paulet H, Gisselbrecht M, Saint-Jean O. Clinical usefulness in geriatric patients of combining CHADS2 and HEMORR2HAGES scores to guide antithrombotic prophylaxis in atrial fibrillation. Aging Clin Exp Res. 2010;22(4): 289-294.

36. Pisters R, Lane DA, Nieuwlaat R, de Vos CB, Crijns HJ, Lip GY. A novel user-friendly score (HAS-BLED) to assess 1-year risk of major bleeding in patients with atrial fibrillation: the Euro Heart Survey. Chest. 2010;138(5):1093-1100.

37. Levey AS, Coresh J, Greene T, et al. Using standardized serum creatinine values in the modification of diet in renal disease study equation for estimating glomerular filtration rate. Ann Intern Med. 2006;145(4): $247-254$.

38. Connolly SJ, Ezekowitz MD, Yusuf S, et al. Dabigatran versus warfarin in patients with atrial fibrillation. $N$ Engl J Med. 2009;361(12): $1139-1151$.

39. Lip GY. Don't add aspirin for associated stable vascular disease in a patient with atrial fibrillation receiving anticoagulation. BMJ. 2008; 336(7644):614-615.

40. Heidbuchel H, Verhamme P, Alings M, et al. European Heart Rhythm Association Practical Guide on the use of new oral anticoagulants in patients with non-valvular atrial fibrillation. Europace. 2013;15(5): 625-651.

41. Hart RG, Pearce LA, Aguilar MI. Meta-analysis: antithrombotic therapy to prevent stroke in patients who have nonvalvular atrial fibrillation. Ann Intern Med. 2007;146(12):857-867.

42. van Walraven C, Hart RG, Connolly S, et al. Effect of age on stroke prevention therapy in patients with atrial fibrillation: the atrial fibrillation investigators. Stroke. 2009;40(4):1410-1416.

43. Mant J, Hobbs FD, Fletcher K, et al. Warfarin versus aspirin for stroke prevention in an elderly community population with atrial fibrillation (the Birmingham Atrial Fibrillation Treatment of the Aged Study, BAFTA): a randomised controlled trial. Lancet. 2007;370(9586):493-503.

44. Rash A, Downes T, Portner R, Yeo WW, Morgan N, Channer KS. A randomised controlled trial of warfarin versus aspirin for stroke prevention in octogenarians with atrial fibrillation (WASPO). Age Ageing. 2007;36(2):151-156. 
45. Lip GY, Boos CJ. Antithrombotic treatment in atrial fibrillation. Heart. 2006;92(2):155-161.

46. Donadini MP, Douketis JD. Combined warfarin-aspirin therapy: what is the evidence for benefit and harm and which patients should (and should not) receive it? J Thromb Thrombolysis. 2010;29(2):208-213.

47. Olesen JB, Lip GY, Hansen ML, et al. Validation of risk stratification schemes for predicting stroke and thromboembolism in patients with atrial fibrillation: nationwide cohort study. BMJ. 2011;342:d124.

48. Reardon G, Nelson WW, Patel AA, Philpot T, Neidecker M. Warfarin for prevention of thrombosis among long-term care residents with atrial fibrillation: evidence of continuing low use despite consideration of stroke and bleeding risk. Drugs Aging. 2013;30(6):417-428.

49. Friberg L, Rosenqvist M, Lip GY. Net clinical benefit of warfarin in patients with atrial fibrillation: a report from the Swedish atrial fibrillation cohort study. Circulation. 2012;125(19):2298-2307.

50. Albers GW, Bittar N, Young L, et al. Clinical characteristics and management of acute stroke in patients with atrial fibrillation admitted to US university hospitals. Neurology. 1997;48(6):1598-15604.

51. Brass LM, Krumholz HM, Scinto JM, Radford M. Warfarin use among patients with atrial fibrillation. Stroke. 1997;28(12):2382-2389.

52. Gurwitz JH, Monette J, Rochon PA, Eckler MA, Avorn J. Atrial fibrillation and stroke prevention with warfarin in the long-term care setting. Arch Intern Med. 1997;157(9):978-984.

53. Munschauer FE, Priore RL, Hens M, Castilone A. Thromboembolism prophylaxis in chronic atrial fibrillation. Practice patterns in community and tertiary-care hospitals. Stroke. 1997;28(1):72-76.

54. Waldo AL, Becker RC, Tapson VF, Colgan KJ. Hospitalized patients with atrial fibrillation and a high risk of stroke are not being provided with adequate anticoagulation. J Am Coll Cardiol. 2005;46(9): 1729-1736.
55. Schulman S, Beyth RJ, Kearon C, Levine MN. Hemorrhagic complications of anticoagulant and thrombolytic treatment: American College of Chest Physicians Evidence-Based Clinical Practice Guidelines (8th Edition). Chest. 2008;133(6 Suppl):257S-298S.

56. Poli D, Antonucci E, Testa S, Tosetto A, Ageno W, Palareti G. Bleeding risk in very old patients on vitamin $\mathrm{K}$ antagonist treatment: results of a prospective collaborative study on elderly patients followed by Italian Centres for Anticoagulation. Circulation. 2011;124(7):824-829.

57. Wolf PA, Abbott RD, Kannel WB. Atrial fibrillation as an independent risk factor for stroke: the Framingham Study. Stroke. 1991;22(8): 983-988.

58. Gage BF, Boechler M, Doggette AL, et al. Adverse outcomes and predictors of underuse of antithrombotic therapy in medicare beneficiaries with chronic atrial fibrillation. Stroke. 2000;31(4):822-827.

59. Apostolakis S, Lane DA, Guo Y, Buller H, Lip GY. Performance of the HEMORR(2)HAGES, ATRIA, and HAS-BLED bleeding riskprediction scores in patients with atrial fibrillation undergoing anticoagulation: the AMADEUS (evaluating the use of SR34006 compared to warfarin or acenocoumarol in patients with atrial fibrillation) study. $J$ Am Coll Cardiol. 2012;60(9):861-867.

60. Man-Son-Hing M, Laupacis A. Anticoagulant-related bleeding in older persons with atrial fibrillation: physicians' fears often unfounded. Arch Intern Med. 2003;163(13):1580-1586.

61. Diug B, Evans S, Lowthian J, et al. The unrecognized psychosocial factors contributing to bleeding risk in warfarin therapy. Stroke. 2011; 42(10):2866-2871.

62. Ogbonna KC, Jeffery SM. Risk versus benefit of non-vitamin K dependent anticoagulants compared to warfarin for the management of atrial fibrillation in the elderly. Drugs Aging. 2013;30(7):513-525.
Clinical Interventions in Aging

\section{Publish your work in this journal}

Clinical Interventions in Aging is an international, peer-reviewed journal focusing on evidence-based reports on the value or lack thereof of treatments intended to prevent or delay the onset of maladaptive correlates of aging in human beings. This journal is indexed on PubMed Central, MedLine,

\section{Dovepress}

CAS, Scopus and the Elsevier Bibliographic databases. The manuscript management system is completely online and includes a very quick and fair peer-review system, which is all easy to use. Visit http://www.dovepress. com/testimonials.php to read real quotes from published authors. 